\title{
DOCUMENTOS
}

\section{Reproducción y Comentario de Algunas Prosas Olvidadas de Ramón López Velarde}

$\mathrm{D}$ URANTE muchos años se conocía generalmente la obra de Ramón López Velarde por las mal llamadas Obras completas (México: Editorial Nueva España, I944), un tomo que incluye La sangre devota (I9I6), Zozobra (1919), El son del corazón (1932) y las prosas de El minutero (x923). Desde aquel entonces muchos investigadores, entre los cuales es grato mencionar a Luis Noyola Vázquez, Carlos Villegas y Emanuel Carballo, se pusieron a rescatar del olvido versos y prosas del poeta zacatecano. En el año de 1952 Elena Molina Ortega publicó El don de febrero y otras prosas (México: Imprenta Universitaria, 1952), recopilación de noventa textos con unas notas bibliográficas, y Poesías, cartas, documentos e iconografia (Ibidem), que recoge veintiún poemas. Gran parte de estas obras ya habían sido publicadas en revistas (Armas y Letras, México en el arte, Cuadernos Americanos, etc.) y su novedad, por lo tanto, fue muy relativa. No es del caso aludir aquí a todos los irritantes defectos de los trabajos de Molina Ortega, ni a las omisiones imperdonables de textos ya dados a conocer con anterioridad. ${ }^{1}$ Sin embargo, es justo afirmar que ella nos ha rendido un importante servicio al reunir en haz compacto esos escritos dis-

1 Nosotros nos ocupamos, con cierta extensión, de estos trabajos de Elena Molina Ortega en "Nuevos estudios sobre López Velarde", Revista Hispánica Moderna, XIX (Núms. 1-4, enero-diciembre, 1953), pp. 94-99. Sobre el mismo asunto hay otros dos ensayos que ofrecen importantes precisiones: Carlos Villegas, "Nueva investigación sobre Ramón López Velarde", Cuadernos americanos, XI (Núm. S, sept-octubre de 1952), pp. 280-283 y José Luis Martínez, "Huellas de Ramón Iópéz Velarde", Univęsidad de México, VI (Núm, 65, mayo de 1952), pp. 13-15, 
persos de López Velarde. Posteriormente la misma investigadora publicó un tomo de Prosa politica (México: Imprenta Universitaria, I953), cuyo contenido no nos interesa aquí. En los últimos años, Francisco González Guerrero dio a conocer, con comentario, un cuento de López Velarde, y Adalberto Navarro Sánchez, por su parte, reprodujo una olvidada nota de tipo bibliográfico.

Ahora bien: algunas prosas que recopiló Molina Ortega tienen valor permanente y con derecho pudieran figurar al lado de las de El minutero. No así, pues, las poesías que pudo exhumar, todas ellas de la etapa juvenil de López Velarde. Al reseñar en esas mismas páginas (Núm. 37, octubre de 1953, pp. r86-I89) la primera edición de Poesías completas y El minutero, preparada por Antonio Castro Leal, lamentábamos la no inclusión de una muestra de las prosas dadas a conocer por Molina Ortega. Dicha edición, de la cual hay una segunda de 1957 , sí incotpora una sección de "Primeras poesías", obras que francamente no agregan mucho a la figura y fama de López Velarde poeta. Como bien se sabe, él mismo las excluyó de su primer poemario La sangre devota.

Presentamos en este trabajo, en orden cronológico, una serie de prosas olvidades y tres notas bibliográficas, las cuales no han sido publicadas en otra parte con una sola excepción..$^{2}$ El interés - considerable en dos o tres casos - lo destacamos en el breve comentario que acompaña a cada una de ellas, pero digamos, de una vez, que el valor artístico de ciertas prosas aquí reproducidas es muy relativo. Esos escritos los hemos encontrado en las hemerotecas y bibliotecas públicas de México, así como en la biblioteca particular del amigo y escritor Julio Torri, a quien quisiéramos expresar formalmente nuestra gratitud por habernos proporcionado ciertas publicaciones muy difíciles de conseguir. Además, con su acostumbrada bondad y gentileza, el estimado hermano del poeta, doctor Jesús López Velarde, con quien hemos compartido gratas horas de cordial conversación sobre la obra de Ramón, nos proporcionó, de sus archivos particulares, la primera prosa aquí presentada. A él le expresamos nuestras más sinceras gracias. ${ }^{3}$

i2 Sin las correspondientes señas bibliográficas Emmanuel Carballo reproduce la reseña de López Velarde sobre El plano oblicuo de Alfonso Reyes en una nota de su excelente trabajo "Ramón López Velarde en Guadalajara", Et Caetera (Guadalajara), Núm. 9-10, 1952, pp. 48-49.

3 No recogemos aquí la prosa "La magia de Amado Nervo", un fragmento de su estudio más extenso que apareció, con casi el mismo título y en forma definitiva, en Amado Nervo y la critica literaria (México, 1919). Molina Ortega lo incluye en $E l$ don de febrero $y$ otras prosas, pp. 321-325. Dicho fragmento fue publicado en El Heraldo Ilustrado (Núm. 11, 19 de noviembre de 1919), y to apuntamos sencillamente porque hasta ahora nadie ha advertido su colaboración (verso y prosa) en esta revista capitalina. 
1. "Al fin del año". De la serie "Renglones líricos". San Luis Potosí (1913).

Al presentar esta primera prosa, una romántica divagación sobre el tiempo y la muerte, permítaseme una previa pero necesaria historia bibliográfica. Con el seudónimo de Tristán, Ramón López Velarde publicó en El Eco de San Lais ( $\mathrm{I}_{913}$ ) una serie de dieciocho prosas bajo el título de "Renglones líricos". En I945 el director de este periódico, Manuel Sancho, proporcionó a la nueva revista Estilo (Núm. I, I945, Pp. I3-I7) dos de estas prosas ("Nuestra casa" y "La viajera"), que fueron copiadas, según la nota bibliográfica, de los números $34 \mathrm{y} 4 \mathrm{I}$ respectivamente de El Eco de San Luis.

En I950 Cuademos Americanos (Núm. 5, sept-octubre de 1950, Pp. 25I-28I) publicó, sin señas bibliográficas sobre las prosas individuales, esos escritos semanales tomados de la colección completa de dicho periódico, del cual sólo existen dos colecciones, según la nota que acompaña su presentación. Llegan a dieciocho, como antes fue indicado en la nota de Estilo.

Elena Molina Ortega, en 1952, recogió diez y seis de estas prosas en su ya citado $E l$ don de febrero. Inexplicablemente dejó de reproducir "Hoja de otoño", la primera prosa que apareció en el número citado de Cuademos Americanos, y omitió inteligentemente "Aquel día" que antes había aparecido en El Regional de Guadalajara en el año de ryog.

Ahora bien: con respecto a "Al fin del año" hay otros problemas de naturaleza bibliográfica muy difíciles de resolver, sobre todo porque nos

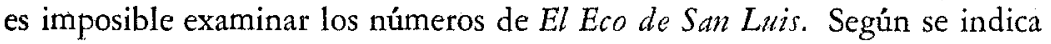
la prosa forma parte de los llamados "Renglones líricos", pero la versión escrita a máquina que pude copiar (y cuyos errores más obvios los he procurado corregir) no tiene indicación de su lugar de publicación en San Luis. Otra cosa notable: el escrito va firmado con el seudónimo de Teófilo y ya no de Tristán. Sin embargo, la última prosa del grupo, según Molina Ortega, es "En el aire", 22 de diciembre, y la que ahora presentamos, fechada el 29 de diciembre, la sigue exactamente en una semana, ritmo acostumbrado en la publicación de esas prosas líricas.

Al dar a conocer esta prosa, la cual bien puede ser de López Velarde, tenemos que admitir que la presentamos con ciertas pequeñas reservas. El poder consultar El Eco de San Luis bien pudiera disiparlas. Pero ¿por qué cambió de seudónimo? ¿Habrá otras prosas así firmadas en el mismo lugar? ¿O fue publicada en otro periódico de San Luis Potosí? ¿Puede que 
sea un escrito rigurosamente inédito? Estas interrogaciones las dejamos pendientes, hasta el momento de poder ofrecer mayores precisiones sobre la obrilla en cuestión. Por otra parte, "Al fin del año" no agrega ciertamente nada a la fama de López Velarde prosista. Es una prosa francamente mediocre que no tiene la calidad aun de otras que datan de la misma época. Sin embargo, por su tono de suave romanticismo y su factura lírica coincide con las divagaciones de "Renglones líricos".

II. "Luna de miel", cuento publicado en La Ilustración Semanal (I9I4).

En 1954 Francisco González Guerrero publicó el único cuento conocido de López Velarde, "El obsequio de Ponce", que apareció en El Mundo Ilustrado (1913).4 En la nota que acompaña la reproducción de ese relato dice González Guerrero: ". . De haber seguido este filón, López Velarde seria hoy uno de nuestros mejores cuentistas. Pieza solitaria, tiene por sí misma una doble significación reveladora: la autobiográfica, que puede sacarse del examen de sus ideas, y la literaria en cuanto viene a mostrarnos un aspecto inadvertido de su obra." 5

En los dos cuentos el problema es el mismo, aunque enfocado desde una muy diferente perspectiva. En "El obsequio de Ponce" el protagonista no se va a casar con su novia Rosario por su pesimismo, un sincero pesimismo que López Velarde también evoca en otras prosas suyas ("Nuestra casa", "Clara Nevares" y "Fresnos y álamos"). Precisamente por tal actitud se niega a "fundar un taller de sufrimiento, abrir una fuente de desgracia, instituir un vivero de infortunio..." (p. 42) Y por eso piensa entregar, pues, su novia al antiguo compañero de la Preparatoria, para que se casaran y "se encerrasen en el cubo sombrío y asfixiante de la torre de la fecundidad, donde Rosario, como todas, multiplicaría los ayes y las blasfemias de la estirpe de Caín" (p. 46). Desde luego, como también lo advierte González Guerrero, aquí asoma uno de los temas insistentes de López Velarde: el ímpetu amoroso y el miedo a la perpetuación de la especie. Esa misma preocupación la hallamos en "Obra maestra", "Meditación en la Alameda" y en otros escritos del poeta.

En "Luna de miel" el asunto es, una vez más, el matrimonio, pero ahora uno realizado que termina en irónica desilusión para la mujer al dar-

4 "López Velarde cuentista", Las letras patrias (Núm. 3, julio-septiembre de 1954), pp. 39-40. El cuento reproducido ocupa las páginas $41-47$ de la citada revista.

5 Ibidem, p. 40. 
se cuenta de que los elogios que el marido dirige a su busto no son más que huecas frases aprendidas en el manuscrito del amigo literato recién fallecido. Se advierte otra diferencia entre los dos cuentos: en el primero, el autor dedica más espacio a divagaciones de tipo introspectivo, mientras que, en el segundo relato, hay pocas expansiones que desvían la pura narración de los hechos pertinentes.

Lo más notable de "Luna de miel", en nuestra opinión, es la fina ironía con que López Velarde desarrolla su tema - un tema por cierto no muy novedoso- una ironía que aparece con toda claridad desde el primer momento y sobre todo cuando al final del primer párrafo afirma: "La señora de Galindo necesitaba un esposo que superara en algo a la generalidad de los mortales." Ya en ese instante se inicia el juego con el lector. El coqueteo se hace bien patente y hasta permite anticipar en parte el desenlace cuando, a la simpática presentación de la dama, sigue la más bien prosaica del catedrático de historia. Notoria es, desde luego, la fina ironía de López Velarde, una actitud ante la vida seguramente aprendida, por lo menos en parte, a través de sus lecturas de Anatole France, uno de los autores predilectos del mexicano. ${ }^{6}$

Ese cuento interesa por ser sencillamente otra muestra de un aspecto casi desconocido de la obra de López Velarde. Tiene, por lo demás, cierta fluidez narrativa que logra captar la simpatía del lector, aunque carece de la dignidad literaria de otros escritos suyos en prosa. Lo mejor de López Velarde prosista se encuentra en sus prosas líricas y ensayísticas donde revela tanta originalidad, de fondo y de forma, como en su ya consagrada poesía. No sería justo, sin embargo, olvidarnos de la muy temprana fecha de su composición. Y finalmente "Luna de miel" no deja de revelar el talento irónico y satírico del autor.

III. "Dolor de inquietud", prosa publicada en La llustración Semanal (I914).

Si el relato anterior es una de las muy contadas muestras que se conocen hasta ahora de la prosa cuentística de López Velarde, la que ahora comentamos, en estilo y en composición, es más bien típica de su arte de prosista. Sus prosas de creador, desde temprano y hasta su plena madu-

- Un dato desconocido: López Velarde fue traductor de Anatole France en una ocasión. En la Revista de Revistas (Núm. 254, 21 de febrero, 1915, pp. 13-14) aparece "Misticismo y Ciencia" de Anatole France, traducido especialmente pot Ramón López Velarde según dice la nota que acompaña esta versión. 
rez artística, suelen ser divagaciones o esbozos líricos sobre sus propias angustias y preocupaciones espirituales. Carecen, por lo tanto, de verdaderos esquemas narrativos y fluctúan entre apuntes autobiográficos, crónicas periodísticas y poemas en prosa.

El escrito que nos ocupa ahora se destaca singularmente por ser la más temprana, y quizá la más lúcida, exposición en forma lírica y alegórica de la dualidad dramática de su propia conciencia. La dualidad se establece entre las incitaciones de la carne y del espíritu, entre el pecado y la virtud, entre la tierra y el cielo. Ese conflicto de fuerzas opuestas, en constante diálogo simultáneo, es la modalidad quizá más característica de gran parte de su obra madura, sobre todo en Zozobra, su mejor poemario. López Velarde define ya en esta prosa - y no olvidemos la fecha de I9I4- la coexistencia de esas dos posiciones antagónicas cuando escribe, con una típica imagen ritualística: "...Vamos sin rumbo, solicitados por imanes opuestos, y si una gota de cera nos da el éxtasis, la otra nos quema con lumbre sensual". Se precisan, un poco después, esas mismas condiciones contradictorias de su alma al afirmar: ". . Ias funciones de la bestia se confunden con los más altos ejercicios espirituales, pues no acertamos a conciliar los unos con los otros". La palabra clave es conciliar, porque precisamente para López Velarde su problema fue la incapacidad de conciliación o su indecisión, si se quiere, entre los dos extremos del deseo erótico y de la fe heredada. Por lo tanto, su fórmula espiritual ha de buscarse entre esos dos polos íntimos, en la vacilación y en la oscilación entre ellos.

La prosa continúa con una serie de variaciones (lino de Verlaine frente a las sedas de la concupiscencia) sobre el mismo tema principal. $\mathrm{Y}$, ya iniciada la alegoría del sexo en la forma del centauro pagano, vuelve a concretarse la pareja de opuestos: "Somos a un tiempo sacerdotes sacrílegos del misticismo y paganos traidores de sus amables diosas". Fracasa, pues, el impulso erótico y conviene que ahora recordemos que en muy contadas ocasiones López Velarde canta el triunfo amoroso. Lo que sí exalta, con toda vehemencia, es el deseo erótico como, por ejemplo, en el poema "Hormigas". Y, por otra parte, bien claras en su obra son las huellas de frustración y de anhelo por algo que hubiera podido ser.

Finalmente, como el escritor mismo afirma, encuentra en la conciencia de ese dolor de "la inquietud pecaminosa" el mérito de la existencia, tema tratado más tarde cuando escribe, en "Malos réprobos y peores bienaventurados", las siguientes palabras: "Hoy por hoy, quizá nuestra única grandeza moral consiste en la pugna que nos roe las entrañas. Somos po- 
linomios cuyos términos discordes hierven sin tregua..." A la pode. rosa fuerza del demonio, sin embargo, insinúa López Velarde, se opone la amada pura y sana que va adelante, después de su discurso filosófico, "como guía providencial que llevase, entre las manos frágiles, una luz". Estas palabras recuerdan ciertos versos de uno de los buenos poemas de La sangre devota, un poema de r9rs y por lo tanto de la última cosecha cuando ordenaba la edición definitiva de su primer libro:

He aquí que en la impensada tiniebla de la muda ciudad, eres un lampo ante las fauces lóbregas de mi apetito;

("En las tinieblas húmedas...")

o quizá más íntimamente una composición excluida por el poeta de su obra, de la cual transcribimos los siguientes versos:

Me despido... Ella guía,

llevando, en un trasunto de Evangelio, en las frágiles manos una luz.

Pero apenas llegados al umbral

-suspiro de alma en pena

o soplo del espíritu del mal-,

un golpe de aire mata la bujía...

Aúlla un perro en la calma sepulcral).

Fue así como Fuensanta y el idólatra nos dijimos adiós en las tinieblas

de la noche fatal...

("El adiós")

No sólo es "Dolor de inquietud" una de las más claras expresiones de su propio drama íntimo - y por eso sumamente útil en la nada fácil interpretación de su obra total- sino que al mismo tiempo reafirma la estrecha unidad que siempre existía entre el verso y la prosa de Ramón López Velarde. Por lo demás, el oído del lector oye constantemente ecos de

7 Sigue diciendo en la misma prosa: "Prosigamos en la triste grandeza de la alternativa que nos roe las entrañas y saludemos con rendimiento al cordero $\mathrm{y}$ al gallo, ya que carecemos de la castidad del uno, encomiada por la Antigua y la Nueva Irey, y del rijo indefectible del otro, cuya mirada redonda, que se ribetea de una digna púrpura, vislumbra los hombros, acogedores y consoladores, de las huríes". El don de febrero y otras prosas, p. 267. 
motivos temáticos y hasta tonales, así como fórmulas expresivas predilectas del escritor. A puntar todos esos recuerdos sería en extremo fatigoso y, por lo tanto, nos permitimos un solo ejemplo: "Nuestro afán es un corcel sin brida, que se revuelve, escarba la tierra, se desmelena y relincha, pero no avanza." Con una pequeña sustitución de animal, se piensa inevitablemente en "Obra maestra" (prosa) y, a la vez, en ciertos versos del poema "Para el zenzontle impávido". Repetimos, pues, que esta prosa, por su fecha temprana, es significativa no sólo dentro de la trayectoria vital de López Velarde; sino que también comprueba, una vez más, que no todo el amor de La sangre devota es puro y casto sin mayores complicaciones espirituales.

IV. Tres prosas de El Nacional. Diario libre de la Noche. (1916).

López Velarde empezó a colaborar en el periódico de Gonzalo de la Parra desde fines de I9I5 cuando éste se llamaba El Nacional Bisemanal. Sus colaboraciones eran, por lo general, de tema provinciano o de tipo autobiográfico. En I952, al coleccionar estas crónicas, Elena Molina Ortega dejó de reproducir las tres prosas que ahora of recemos. La omisión de dos de ellas ("En favor del poetastro" y "Carmelita y el tren eléctrico") no le pasó inadvertida a Carlos Villegas. ${ }^{8}$

Las dos primeras prosas que reproducimos no of recen grandes novedades, ni de estilo ni de concepto; apenas interesan dentro de la totalidad de su obra; y no revelan al excelente prosista que ya en rgr 6 fue López Velarde. De paso, algunas de las muy buenas prosas de El minutero remontan a esa misma fecha. Tanto "En favor del poetastro" como "Carmelita y el tren eléctrico" son fragmentos ocasionales, escritos, eso sí, con buen sentido de humor e ingeniosidad sobre temas tratados con jocosa $y$ penetrante ironía.9

s Carlos Villegas, Artículo citado.

9 Quizá convenga recordar, con respecto a "En favor del poetastro", que esta prosa pone de relieve, una vez más, la alta estima que López Velarde tenía de la capacidad artística de María Enriqueta, a quien alude en otras ocasiones y a quien dedica toda una prosa. La obra de ella, junto con la de Sor Juana, brilla no sólo por sus méritos intrínsecos sino también por la ley fatal del contraste. Además López Velarde escribió: "..Yo diría que su principal atributo [el de María Enriqueta] es la naturalidad. Nada, dirán algunos. Casi todo, decimos otros. Todo diré yo, aquilatando el caso singular: una mujer sin ripios y, más aún, que continúa mujer. Porque el lector, si es ducho, convendrá en que Sor Juana y doña Emilia Pardo Bazán nos dan el olvido de su género gramatical, arrollándonos con su ímpetu" masculino". "María Enriqueta", : $E l$ don de febrero y otras prosas, p. 282. Esto lo citamos porque puede relacionarse también con algunos conceptos expresados en "Carmelita y el tren eléctrico". 
De muy distinta factura y de calidad artística infinitamente superior es la prosa titulada "Los obreros equilibristas". En primer lugar, el tema es de índole social-política y la prosa, por lo tanto, interesa en este sentido para aclarar un tanto las no siempre muy claras simpatias políticas del poeta. Rebasa los límites de este breve comentario detenernos en una exégesis de los conceptos aquí expresados y de la política de López Velarde. Basta decir sucintamente que en esta prosa adopta una posición intermedia entre lo que pudiéramos denominar "reacción" y "revolución". Es decir, no se cierra a las exigencias del presente ni a las promesas del futuro, pero, al mismo tiempo, no quiere que se olvide de lo más valioso de la tradición. Al impugnar el socialismo y el sindicalismo del momento, no deja de ver un peligro en la demagogia que recomienda el divorcio del pasado y el descuido del futuro. Sin embargo, todo eso - y otras observaciones que merecen tenerse en cuenta en la consideración de su posición políticanos parece lo de menos interés en una prosa que vale, a nuestro modo de ver, no por sus conceptos, sino más bien por sus aciertos estilísticos. Ya vemos al prosista de talento que sabe expresar, en una serie de certeras y enérgicas imágenes, sus ideas ahora de tipo más bien social. No es del caso analizar detenidamente en una seca nota bibliográfica las técnicas imaginativas de López Velarde, pero quisiéramos advertir que ese escrito tiene importancia desde un punto de vista de su evolución estilística. Puede relacionarse, pues, con ciertos procedimientos característicos de sus prosas más líricas y más elaboradas de su plena madurez artística. Uno de sus recursos favoritos fue el de buscar un simbolo central, mediante el cual intentaba expresar más adecuadamente todos los variados matices de su propia emoción en una insistente serie de variaciones sobre el mismo tema. La misma técnica, desde luego, la hallamos en esta prosa, ya en el título mismo donde aparece una imagen de las más predilectas del poeta, la de suspensión y de oscilación, una imagen que aparece y reaparece al desarrollar el motivo que le inspira su comentario sobre la situación social-política del país.

V. "Estos dos mancebos...", nota publicada en El Universal (rgrg). r92I).

Esta pequeña prosa no tiene gran importancia por lo que dice-bien poco en verdad- pero sí interesa mucho desde el punto de vista histórico por ser la presentación de dos jóvenes poetas que, con los años, no defraudaron las esperanzas optimistas de López Velarde. La recogemos aquí por- 
que indica los lazos de amistad que unían al poeta ya maduro con la joven generación de poetas que iniciaban su carrera literaria hacia aquellos años. También conviene que recordemos que a los poetas de esta generación, que más tarde llegó a ser llamada de "los contemporáneos", se deben algunos de los mejores y más penetrantes estudios críticos que tenemos sobre López Velarde (Villaurrutia, Torres Bodet, Ortiz de Montellano, Gorostiza)..$^{\text {.to }}$

VI. Tres notas bibliográficas, publicadas en México Moderno (I920I92I).

(a) Sobre El plano oblicuo de Alfonso Reyes.

Quizá sorprenda algo que haya pocas alusiones a Alfonso Reyes en la obra de López Velarde y, más aún, que las de Reyes sobre el poeta zacatecano sean algo menos que entusiastas. Dejando de lado la validez de los juicios aquí expresados, por cierto discutibles a estas alturas, lo que se pone de manifiesto en seguida - para el que conoce la obra de López Velarde- es su perfecta consecuencia con sus propias ideas sobre la tarea literaria.

Desde muy temprano (su prosa "El secreto" es de r9r3, donde se encuentra un primer esbozo de estas ideas) López Velarde insiste en que la emoción misma, pura y neta, es necesariamente la base de toda creación acertada. Teme precisamente que el saber intelectual estropee la inmediata contemplación del sentimiento. No se cansa jamás de repetir que la emoción debiera triunfar sobre la vanidad de los cerebralismos que dañan la fantasia creadora. En más de una ocasión exalta las obras literarias libres de especulación, sin doctrina y teorías, porque para él la obligación sagrada del poeta fue la de provocar sensaciones. Por lo tanto, las pequeñas reservas que parece tener ante esa temprana obra de Reyes están arraigadas en su propio credo estético. Sin embargo, sólo advierte un posible riesgo en la literatura de Alfonso Reyes, y afirma que sus fibras vitales, su malicia y su numen le salvarán de lo meramente discursivo. Y está seguro, por lo demás, de que "seguirá dándonos, como hasta aquí, el esqueleto de la

10 En otro escrito, fechado en 1917, mostró su adhesión a los poctas jóvenes. İn él afirma lo siguiente: "Yo debo confesar que estaba prevenido contra los jóvenes halcones como los llama Rafael López. Pero también he de decir aquí que me han desarmado, convenciéndome de su aptitud apolínea. Es verdad que sigo incrédulo de no pocos mancebos, sin ponderación y sin enmienda, mas en últino análisis, me he vuelto partidario de esa hábil adolescencia en que militan, entre otros muchos José Antonio Muñoz, Martín Gómez Palacio y Carlos Pellicer Cámara. En su compacta legión vibra y sobra el ímpetu y ondean las esperanzas ilesas. Alégrome de poder declarársemeles adicto". "Poesía y estética", Ibídem, pp. 310-311. 
idea y la emoción palpable, la vitrina en que sueñan las materias grises y el tallo en que respiran los cinco sentidos."

Otra cosa merece breve mención: con respecto a los poetas que cultivan la prosa (y López Velarde prefiere a Reyes fuera de la lírica), el poeta que se caracteriza por su disciplina netamente artística suele sobresalir como prosista. Se nos ocurre que la misma idea podría ser aplicada a López Velarde mismo, porque, en nuestra opinión, fue tan gran prosista como poeta, si bien su fama reside en el verso y no en la prosa mucho menos conncida y estudiada.

\section{(b) Sobre El libro del trópico de Arturo Ambrogi.}

De esta escueta nota es el párrafo final, desde luego, que tiene más interés, porque en él López Velarde insiste en cómo los temas criollos pueden ser tratados con dignidad estética si los aborda un escritor de verdadero talento. Así lo afirmó tambiẻn en el prólogo a Campanas de la tarde de Francisco González León. Por lo tanto esas palabras se relacionan claramente con lo que López Velarde mismo llama criollismo en el arte, cuya teoría se desarrolla más ampliamente en otras prosas suyas ("Enrique Fernández Ledesma", "Melodía criolla" y "Novedad de la patria"). Además advierte aquí el gran peligro que no saben evitar los escritores mediocres quienes, al ocuparse de temas autóctonos, caen por falta de vocación artística "en los inventarios de un servil naturalismo".

(c) Sobre Campo argentino y Vèrsos de Negrita de Fernández Moreno.

Esta reseña bibliográfica cobra singular relieve desde la perspectiva histórica si pensamos en el hecho de que Fernández Moreno, en la poesía postmodernista argentina, ocupa un lugar muy parecido al de López Velarde mismo en México. Destaquemos brevemente lo más sustancioso de sus observaciones. En primer lugar, López Velarde no se preocupó mucho por la forma poética y cultivó con frecuencia un verso que desdeñara ciertos halagos musicales para que éste se amoldase a la más adecuada expresión de sus propias emociones. Es decir, se permitió algunas libertades con las supuestas leyes de la versificación. Sin embargo, nos recuerda certeramente que siempre el sentimiento, para convertirse en poesía, exige una forma (o contorno como dice López Velarde) "sobre los intentos de anarquía y los 
simples desenfados de ejecución". Tanto Fernández Moreno como López Velarde acogieron temas cotidianos en su obra poética, un rasgo que sitúa a los dos dentro de las corrientes postmodernistas. Con acierto se señala el. peligro de un arte intencionalmente plegado sobre lo cotidiano: una recaída en lo trivial. Sin embargo, las cosas mismas no tienen jerarquía en la lírica y dijo una vez el mexicano: ". . la misma poesía de las cosas humildes es rectora, jamás subordinada." 11 Ambos poetas, por su capacidad artística, se salvaron de "las especies toscas" que suelen amenazar una lírica que recoge de preferencia asuntos ordinarios y humildes. Y, finalmente, aplaude a Fernández Moreno por ciertas cualidades que él mismo considera esenciales en el verdadero poeta.

La reproducción de estas prosas de Ramón López Velarde se justifica más por razones bibliográficas que por su propia calidad artística. Sin embargo, sobre todo dos de ellas ("Luna de miel" y "Dolor de inquietud") son significativas por razones que indicamos oportunamente; otras sirven para redondear ciertas preocupaciones espirituales y estéticas del escritor.

University of Cbicago

\section{Allen W. Phillips}

\section{RENGLONES LIRICOS}

\section{Al Fin del AÑo}

i or qué - dijiste aquella tarde en que, con tus manos entre las
mías, contemplábamos la declinación del sol, enmedio de una suprema melancolía provocada por la hora, la paz del jardín y la incipiente penumbra, por qué, - dijiste,- cuando los rayos del sol van perdiendo su brillo y las flores recogen sus pétalos, los árboles quedan inmóviles y la fuente murmura más quedo; por qué se siente tristeza como si fuera uno a morir, o como si hubiese perdido una esperanza muy querida, o se hubiese roto un ensueña?. ¿Por qué también cuando está para acabarse un año, como que duele el corazón y en suspirar y en recordar se van las horas; por qué si ayer es como hoy, y como hoy será mañana, y siempre será igual, según me has dicho que alguien escribió? ¿No es, pues cierto

1.1 Estas palabras de López Velarde se hallan en Abel García Cảlix, "Ramón López Velarde", El Universal Ilustrado (Núm. 324, 26 de julio de 1923). 
lo que enseñan y predican los sabios filósofos que afirman que cada día que pasa nos acerca más y más a la muerte, y la muerte es lo mejor? ¿Por qué, pues, sentimos tristezas tan grandes y tan calladas cuando pasan los días con su transcurrir perenne y nos vamos aproximando a la hora final, que será la primera, y una vida ya sin dolor y sin muerte? Tú piensas eso, y no me lo has enseñado y, sin embargo, cuando el sol va trasponiendo los montes, o el año nos da sus últimos días, también te llenas de tristezas, suspiras y meditas y tienen tus ojos vaguedades en el mirar, como si tu alma se fuera muy lejos, o te quedases contemplando una aparición extraña, visible sólo para tí. ¿Por qué será?

Entonces sólo te respondí, con una mirada y con un suspiro, dulce amada mía, porque la hora, el sitio y el espíritu no me enseñaron a decir nada; pero hoy quiero escribirte, por qué es todo eso que me interrogaste.

Sabias filosofías y místicas enseñanzas nos dicen, y es muy cierto que no hay ventura mayor para el que cree y el que espera que la de llegar a la muerte con el alma sin pesadumbres de pecado y morir para vivir eternamente, ya sin temor de nuevas muertes ni de males, ni de extravios. Cierto también que el dejar la vida cuando la muerte llegue, sin ser buscada aun cuando sea deseada, es un dulce bien que cura definitivamente de amarguras y de desesperanzas; pero también es verdad que la vida, cuando ya es vida pasada, tiene el grato prestigio de las cosas nuestras, que amamos por igual, y han sido causas de dolores, y de alegrías. Efimero es el placer y el dolor mismo, con ser más fiel y constante es también transitorio; las esperanzas, las ilusiones, los sueños de encanto y de amor, todo cuanto ocupa el pensamiento y deshace y desvanece y torna en recuerdos el tiempo y el vivir cotidiano; todo el conjunto de vanidades y pequeñeces, de delirios y de quimeras de anhelos y de dolores; el palpitar acelerado por una mirada de tus ojos, el llanto de los míos por tu desamor $\mathrm{y}$ tus desdenes, todo queda en el tiempo que se va, y, como "toda vida pasada fue mejor", de allí que nos duela, nos entristezca y haga ameritar el acabarse de un día, o el finalizar de un año. Todo cuanto hemos sido es ya sólo del tiempo, que, ora amigo, ora hostil, es siempre avaro de lo suyo y guardián celoso de cuanto en su seno dejamos. Apenas si el recuerdo nos enseña, una que otra vez algo de lo pasado que ahora amamos porque fue nuestro y antes no supimos querer porque era un presente o futuro. Nos duele que el tiempo se vaya, por el dolor nuestro que se lleva, por el placer que nos roba, porque pudimos ser felices y no supimos serlo, porque en el tiempo lloramos y él se lleva nuestras lágrimas, porque en el tiempo reímos y él apaga hasta el rumor de nuestras risas. 
Por eso, porque el tiempo es nuestra propia vida, por eso nos contristamos, suspiramos y meditamos al atardecer, o cuando se acerca la noche de San Silvestre.

Es el tiempo panteón de los amores y en él se guardan las cenizas de los ensueños y de las esperanzas, y él tiene en sus ánforas el perfume de las rosas que nuestro dolor hizo mustias al rociarlas con llanto.

Por eso quiero siempre estar mirándote, para que al irse el tiempo, se lleve mi vida transitoria, pero no me robe la luz de tu rostro que es la verdadera vida mía.

\section{TEÓFILO}

San Luis Potosí, 29 de diciembre de I9I3

LunA DE MIEL

La señora de Galindo no era, indudablemente una mujer vulgar. A un tiempo la adornaban la belleza física y el esplendor moral. En su frente, que lucía bajo las ondas tenebrosas del pelo con la blancura pálida de los astros, anidaban pensamientos gentiles. Podía emocionarse con un verso noble, festejar una prosa irónica y hasta entender - mejor que algunos varones consagrados- una doctrina filosófica. Su bondad se traducía en lágrimas ante los infortunios corrientes, ora mirarse una niña coja, ora un anciano ciego, ya el desemparo de unos huérfanos, ya una cuna vacía. La señora de Galindo necesitaba un esposo que superara en algo a la generalidad de los mortales.

¿Osariamos decir que Pedro Galindo desempeñaba un papel marital con la llaneza de cualquier honrado vecino? No, porque habría en ello injusticia. El señor Galindo era catedrático de historia, poseia condecoraciones de gobiernos extranjeros, y por la noche, de sobremesa, elogiaba los encantos de su cónyuge con una retórica espontánea, alada, que constituía para la señora de Galindo la ventura más intima y más gallarda de su luna de miel.

Quince días llevaba ella de ser dichosa en el matrimonio, y esperaba siempre ilusionada la hora de la cena para escuchar las palabras que la loaban con una gracia espiritual.

La luz discreta de la lámpara, el ruido lejano y confuso de la ciudad 
que entraba por la ventana del comedor, los manteles cándidos y la vajilla sobria concurrían a acentuar la complacencia con que la dama oía, después de cenar, su panegírico.

Ninguna extrañeza causaba en la señora de Galindo que éste, en el transcurso de un día, no le dirigiese un solo cumplimiento escogido. Ella sabía que su esposo, solicitado por multitud de asuntos, se reservaba para la cena, como si quisiese dedicar la sobremesa a sus expansiones.

Lo que más cantaba el nocturno trovador era el busto de su compañera. ¡Qué esmerada devoción, qué tenaz lirismo en las alabanzas del busto! Con tono familiar y entusiasta se sucedían los ditirambos:

- En el gro nobiliario que cubre la armonía de tu busto, deberían prenderse, amada, las siete joyas de las siete virtudes. Tu busto es fragante y honesto como una rosa de altar. Hay en tu busto las proporciones moderadas y la esbeltez infantil del de una novicia de leyenda. Tu busto, al apoyarse en el barandal de un convento en ruinas, poblaría los claustros con fantasmas inmemotiales...

La señora de Galindo, arrullándose con aquella música lisonjera, doblaba entre los dedos una esquina de mantel. A la noche siguiente, nuevas variaciones del tema:

- Tu busto, amada, merece que en él descansen las cabezas agonizantes de las doncellas mártires. En tu busto reside la salud que dilata el pecho de las tórtolas. Tu busto produce la paz en los ojos y en el alma inquietos...

Así, de sobremesa en sobremesa, la tonadilla iba prestigiando la luna de miel de la señora de Galindo.

Una mañana llamaron a la puerta. Abrió la dueña de la casa y oyó, de labios de un muchacho, la noticia de que Cristóbal Guerra había fallecido en la madrugada, dejando el encargo de que sus manuscritos se entregasen, como herencia, a su amigo Pedro Galindo. La señora recibió los papeles de Cristóbal Guerra, hombre uraño y desdeñoso de la publicidad, que habia muerto convencido de la vanidad de la imprenta.

Ya en su alcoba, la señora de Galindo comenzó a leer los manuscritos. Barajándolos, tropezó con uno extenso: "Elogio de su busto". Descubrió, 
desde el primer renglón, las frases textuales con que su marido la regalaba en las sobremesas. Una ira sorda la invadió. Halló miserable a quien la incensaba con el perfume de ajeno rosal y ya no miró en el ladroncillo más que la bestialidad del sexo. Lloró con abundancia y a través de su llanto vio simpático al otro, rígido, entre sus cuatro cirios. Y la luna de miel, su luna de miel, ¿qué era ya sino un cirio?

A mediodía, la señora nada dijo de la herencia de Cristóbal Guerra. Vino la noche y al concluir la cena Pedro Galindo ensayó:

-Tu busto, amada...

La señora creía ver, materialmente, que su marido metía el brazo en el ataúd del literato, para despojarlo de su laurel oscuro. Se levantó de su asiento y salió del comedor, diciendo con benevolencia:

-Quiero dormir... Tengo sueño...

\section{RAMón López Velarde}

Para "La Ilustración Semanal"

Abril de 1914

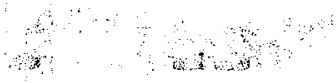

La Ilustración Semanal

(Año I, Núm 28), I3 de abril de r9r4.

\section{DOLOR DE INQUIETUD}

La pareja en la unción de la tarde, descansaba sobre la banca rústica de un jardín. El hablaba con un aire de filósofo antiguo, con grave tranquilidad. Ella ingenua y comprensiva, escuchaba con la atención de una niña curiosa. Los pájaros, en los nidos, oían el discurso sincero.

- "Te he dicho que soy indigno de tí, no por hábito de galantería ni por falsa modestia. En este crepúsculo nada hay galante fuera del sol que incedia [incendia] tu cabeza castaña, ni nada modesto aparte de tus ojos. Soy, en verdad, indigno de la mujer sana porque estoy conta. giado de la enfermedad de mi tiempo: la pecaminosa inquietud. Y la mujer sana es para nuestra inquietud rastrera y sin esperanza, como una flor que se concediese al lodo. Porque nuestra inquietud no es la del mancebo sobre quien gotea la cera ardiente de Psiquis. Vamos sin rumbo, solicitados por imanes opuestos, y si una gota de cera nos da el éxtasis, 
la otra nos quema con lumbre sensual. En vano aspiramos a imprimir a nuestras actividades la serena fisonomía de un taller clásico. En vano fa ciencia se jacta de haber descubierto que la vida es única y que las funciones de la bestia se confunden con los más altos ejercicios espirituales, pues no acertamos a conciliar los unos con los otros. Nuestro afán es un corcel sin brida, que se revuelve, escarba la tierra, se desmelena y relincha, pero no avanza. Todos los anhelos de todas las épocas, al actuar en nosotros, se destruyen y nos dejan inertes. Por escepticismo o por debilidad, ni siquiera logramos fijar un solo deseo, nosotros, los espíritus nutridos de sabiduría secular, los que sonreímos burlonamente en presencia de la escolástica, del racionalismo y del positivismo, los que nos hemos pulido con los mejores ornatos retóricos.

A las veces, caminando en la noche por una calle lavada por la lluvia, las notas de un piano nos sugieren emociones sutiles, paisajes de cuento de hadas, figuras castas, como las del pincel de los frailes pintores que eran dueños de una luz celeste. $\mathrm{Y}$ entonces nos sentimos ligeros como el ala de un ángel y ambicionamos con Verlaine el vestido de lino. Pero aquello no dura más que un instante. Las notas del piano y el ambiente de la calle se vulgarizan, y los fantasmas platónicos se hunden en las aguas muertas de nuestra alma. A las veces, hablándonos en la eminencia de una paz íntima, miramos pasar a la concupuscencia, perfumada y envuelta en sedas. $\mathrm{Y}$ el centauro, espoleado por su aguijón primitivo, emprende la fuga por la llanura fangosa y penetra en la ciudad, y en la llanura y en la ciudad hace estragos. Pero el centauro de hoy es menguado y regresa pronto, con la frente y el busto abatidos, a respirar el viento saludable de las montañas. Somos a un tiempo sacerdotes sacrílegos del misticismo y paganos traidores a sus amables diosas.

No es lo más lamentable que los cascos del centauro conozcan ya las rutas del desencanto. Hay algo más serio: el centauro se ve obligado a desempeñar su papel en la farsa diaria. El centauro que viste jaquet, sombrero alto y botas de casimir, sube al tablado. Una numerosa concurrencia -atea o mogigata, según le conviene- llena las lunetas. En un palco está Deyanira, de abanico e impertinentes. El centauro fracasa. Si al menos tuviese la fortuna del personaje funambulesco que saltó tan sublimemente que fue a perderse en las estrellas ... Mas el centauro salta y cae de manera grotesca, abajo del escenario. La concurrencia ríe. Deyanira misma ríe de su antiguo raptor.

Así, farsantes, vacíos de toda virtud eficaz, sin un solo deseo permanente, somos indignos de la mujer sana, cuya bondad encierra calor 
de nido, cuya labor se consagra a las nobles edificaciones, en cuyos manteles el pan no se resiente de amarguras metafísicas, bajo cuyo techo no se abrigan tristezas trascendentales... Ya ves cómo soy indigno de acariciar tu cabeza castaña. Mi inquietud raya en la demencia, porque al volar, mi generación se lanza al vacío. Tu vuelo es prudente, de avecilla, y si miras venir un viento airado, te posas sobre un rosal, sobre el hombro de un santo de piedra, o cuando más, sobre una esquila del campanario.

Quizá el único mérito real de nuestras existencias consiste justamente en el dolor de la inquietud, de la inquietud trágica que no sospecharon los abuelos, de la inquietud de nuestros corazones que sangran oprimidos en el puño férreo de un demonio. $Y$ tal es el desconcierto, que si esos mismos corazones se libertasen un día, tal vez no atinaran más que a volver al suplicio de los dedos infernales".

Él ha callado. Y como la noche impera ya, la pareja se retira del jardín. La amada va delante, como guía providencial que llevase, entre las manos frágiles, una luz.

RaMón López Velarde

(Para "La Ilustración Semanal")

La Ilustración Semanal

(Año I, Núm. 33), I8 de mayo de 1914.

EN FAVOR Del Poetastro

En Las falsas confidencias, Marivaux aconseja sembrar en todos los espíritus las sospechas que necesitamos. Una de estas sospechas necesarias es la que debemos provocar en el poetastro, induciéndole a que piense que lo juzgamos poeta. Cuando consigamos tal cosa, habremos respondido a una exigencia social y, quizá, hasta individual.

Si para gustar de los bienes más deleitosos es requisito esencial que el contraste nos hiera, convengamos en que el poetastro es el útil reactivo de la poesía. ¿Podríamos vivir sin tedio si no hubiese mujeres feas? $\mathrm{Y}$, sin riesgo de un grave desengaño, ¿podriamos comprometernos a vivir sin fastidio en una ciudad en que no hubiese un plumista de ripios, de deformidades y de ridiculeces? Nuestra debilidad nos volvería insoportable el mundo de la belleza unánime. 
Mi amigo Jacobo Palacios es, en mi conciencia, el reactivo de la poesía. Jacobo escribe. Pinta, Esculpe. Como si dijéramos, un hermafrodita. Gasta unos clavos hasta el borde de la mandíbula y una amabilidad oleaginosa. Su contacto se parece al de un papel en que se atrapan moscas. Jacobo me alcanzó una de estas noches por el Zócalo, mientras yo esperaba un tren. Me dijo por la centésima vez que su flaco son las, hijas de Eva, que sus poemas llegan al rojo blanco y que Mahoma es su adoración. Me hizo el panegírico del divorcio. Por fin, me recitó una extensa versificación en que se confunden lo libinidoso y lo empalagoso. Lo estimulé para ulteriores engendros, y se fue, con un balanceo irreprochable, como de pavo silvestre. Confieso que al caer sobre mí Jacobo, me echó a perder las estrellas y el silencio y las torres de Catedral y la soledad; pero, a poco, caminando entre la miel abundante de sus versos, la tonada dulzona de Jacobo me devolvió el silencio y la Catedral, y su lujuria (que equivale a una mordida con dientes postizos) me restituyó la soledad y las estrellas. $Y$ todavía salí ganando, porque toda la inteligencia de su ser me hizo aquilatar la reserva aristocrática de la media noche.

Que se sepa que abogo también por las señoras, señoritas y niñas que han sido arrastradas en el vórtice de la rima. Contribuyen con algo a que resalte Sor Juana y a que María Enriqueta se eleve en una escala de cumplidos respetos. ¿En qué momento el demonio lírico se coló por los cascos de aquella niña? ¿A qué hora sobrevino el síncope literario a la señora de $\mathrm{H}$ o de $\mathrm{R}$ ? ¿Cómo fue que la señorita de don Pedro o de don Luis se sintió con músculo para una conferencia? Preguntamos impertinentes. Lo que interesa es que todas ellas sirvan para apretar la sombra en que navegan fúlgidamente los escasos nombres femeninos de nuestro arte.

Claro está que quien se metiese a arreglar la casa ajena podría decir estas o parecidas palabras: "Señor ingeniero: su esposa pone a usted en la picota. Confecciona sonetos, habla de reivindicaciónes políticas, diserta sobre Rubén Darío... Y nada de esto puede explicarse por la histeria. Su esposa disfruta de una fisiología recomendable. Hágala usted que ponga punto en boca".

Mas, entonces, ¿no lucirán menos Sor Juana y María Enriqueta?

RAMÓN LóPEz VeLARde

El Nacional. Diario libre de la Noche.

(Núm 46), 15 de julio de ror 6, p. 3. 


\section{Carmelita y el Tren Eléctrico}

Una señorita, cuyo nombre no recuerdo, reclamaba, días ha, desde las columnas de no sé qué diario, el derecho de las mujeres a los asientos del tren eléctrico, a cualquier hora y contra cualquier varón. Más cortesía y menos comodidad, decía la señorita. Además, la reclamante juzgaba vergonzoso el espectáculo de los trenes a la una de la tarde y a las ocho de la noche. Un Colonia Roma o un Santa María eran, para la quejosa, la comprobación de que los hombres ya no somos más que congéneres de Barba Azul, agraviando al mismo.

Supongamos que la señorita se llama Carmen Ortiz, porque necesitamos llamarla con algún nombre. Supongamos que Carmelita ha ardido en ira, yendo de pie y con hambre, a bordo de un tren, por Bucareli o por la Rosa. Supongamos, finalmente, que la razón la asiste en su querella contra los descastados que la dejan ir de pie. Yo, personalmente, estoy de acuerdo en todo con la señorita Ortiz. Ella me permitirá, no obstante, oponer algunos reparos, para que los desvanezca su docto y perspicaz juicio.

Podría un espíritu estrecho hallar algo de incoherencia en los fundamentos de la demanda de Carmelita. (Perdón por la prematura confianza que voy gastando: mi confianza nace de mi simpatía). La señorita Ortiz reclama, unas veces, porque tiene igual derecho que el hombre, porque la liberación de la mujer ha sido ya lograda por el progreso, porque el cerebro de cualquier mujer pesa lo mismo, o más, que el del Presidente Poincaré... Otras veces Carmelita (mi respetuosa admiración me obliga a pedir perdón de nuevo) quiere el asiento del tren simplemente porque es mujer. No seré yo quien discuta un título que toma su fuerza en la galantería, y menos tratándose de la señorita Ortiz, que tanto sabe, y cuya belleza no se ha de frustrar con sus hábitos políticos. Pero su otra argumentación, la juridica, ¿no es deleznable? ¿Cómo podrá Carmelita desalojar de su asiento a un gordo o a un flaco, si existe la teoría del primer ocupante? El flaco y el gordo retorcerían el argumento de la igualdad de derechos, como se dice en la dialéctica escolástica, que, de fijo, es desdeñada por la competencia de la muy avanzada Carmelita. Por otra parte, y si se quiere argüir a derechos, como supongo que quiere argüir Carmelita, es indispensable saber cómo se concilia aspirar al asiento ocupado y hablarse al tú por tú con el hombre, montando a caballo a horcajadas, tripulando bicicleta, pescando una laringitis en las celebraciones 
cívicas, zurciendo estrofas para Bolívar, espumando el puchero de la sociología...

No agrada, ciertamente, la confusión de los géneros. Produce un malestar orgánico ver que en la sopera nadan el pacto social y el desarme universal. El casamiento de la plancha, aunque sea eléctrica, con don Benito Pérez Galdós, no augura buen suceso. Ni se mira muy en su sitio el dedal sobre la uña de un anarquista. Por todo esto, convendría que se deslindasen los campos antes de exigir el asiento de un tren pletórico. Las damas que se limitan a su precario sexo, prosperarán al reclamar, si algún día reclaman. Porque su sexo precario es también su encanto y su firme supremacia. Las damas que se nivelan con los caballeros no deben temer que el nivel se descomponga por asiento más o por asiento menos, pues tal temor sometería al feminismo a contingencias ruines. A contingencias de tren eléctrico...

\section{RAMÓN LÓPEZ VELARDE}

25 de julio

El Nacional. Diario libre de la Noche. (Núm. 55), 26 de julio de rgr6, p. 3.

\section{Los Obreros Equilibristas}

En la obra que versa sobre socialismo y que ha traducido el señor Subsecretario de Hacienda, don Rafael Nieto, hay un pasaje del impugnador de la doctrina, que dice así:

"El remedio para nuestros males sociales propuesto por el socialismo es, en verdad, más radical que el programa del reformador social. Pero la crítica socialista no es más científica. No es científica en absoluto. Exagera los errores y defectos del orden existente, porque los considera sin referencia a los sucesos del pasado y a las posibilidades del presente y del futuro; porque atribuye a la naturaleza humana y a las instituciones humanas una perfectibilidad que no está justificada por la experiencia; y porque considera demasiado simples los principios y procesos sociales".

Tal pasaje, que contiene una sagacidad no muy frecuente, merece un comentario en estos días en que desatentada inquina de los gremios se ha 
revuelto, para nuestro daño, como las cometas versátiles que los muchachos entregan a los ventarrones de marzo.

Uno de los principales riesgos de la difusión del alfabeto y de la profusión de las tribunas de los sindicatos, radica, ciertamente, en el divorcio del pasado y en el descuido del futuro. Para nuestra demagogia, el presente no se nutre del pasado ni mira al porvenir. Los agitadores profesionales simulan apoyar un pie en el vacío y adelantar el otro al vacío. Dan la sensación de los equilibristas que avanzan por una cuerda invisible. Esa conducta aérea, de pelusilla, patética a los ojos de un pueblo pueril, significa la ruptura de la cadena de oro de la tradición y la adulteración de las mejores promesas del día que sigue. El hoy de esas gentes primarias es un hoy hipotético, de generación espontánea y que se prolonga fuera del arco terrestre, en una tangente de ira y de obcecación. Para ellas fue dicha aquella sentencia según la cual al remover un error se desafía el peligro de substituirlo con otro error más grave. Y no es, a fe mia, un retrógrado el autor de la sentencia.

Por fortuna, el ayer y el mañana son invencibles y quien conspira contra su fatalidad, prepara su ruina. Entre el demagogo y el reaccionario hay una afinidad espiritual más franca de lo que pudiera pensarse.

Ramiro de Maeztu, en una crónica de reciente publicación, hacía hincapié en que las páginas mismas de la literatura progresista (algo cruda, para mi gusto), los personajes más sólidos, los netos, son los que representan a la Sombra. La Sombra, con mayúscula, hórrida potestad que todo lo engulle, adquiere ante el cronista una importancia moral y un prestigio vital que la vuelven superior a sus enemigos de blusa y frac. El cronista espera que el frac y la blusa, recapacitando sobre los intereses de la vida y los intereses de los bandos, se reconcilien con la Sombra. Mas en las disputas humanas el espíritu de bandería prevalece sobre el genuino espíritu de la vida. Por esta razón veremos al socialista vacilar a sus anchas en la cuerda artificial de su circo, antes que pisar justamente el campo de la vida, con sus perspectivas de retaguardia y de vanguardia.

Si las extremas derechas se reconciliasen con las extremas izquierdas, cesaría el contraste, condición esencial de la existencia. Pero tal reconciliación, sinónimo de la muerte, no se efectuará. Opónense a ella la constante desigualdad de los temperamentos intelectuales y la curiosa índole del cerebro, que desvirtúa todas las cuestiones prácticas que plantea. Las pasiones derivadas del cerebro desnaturalizan a sus víctimas, desde mucho antes del tiempo en que don Quijote escarmentaba los cueros de vino y metía es- 
panto en los clérigos que acompañaban un cadáver incierto, nocturnamente y a campo traviesa.

El furor sindicalista, en su propaganda espesa, puede denotar buena fe; pero no es fácil que se cure de su opacidad de retina y de su aspereza ética.

Los corifeos, gemebundos o altaneros, conseguirán que se pique el mar en un momento súbito; mas lo que no han de lograr, ora tomen la cosa por la tremenda, ora lloren los kiries, es alterar las leyes del mundo intelectual, promulgadas por encima de la turbulencia de los clubes, ni la fórmula moral de las conciencias, más honda que la triste penuria física y que el deletreo, poco simpático, de los enciclopedistas sastres o albañiles.

Lo que no impide ni impedirá que los gremios se revuelvan, un dia sí y otro no, como chillantes cometas de carnestolendas.

\section{RAMÓN López VELARDE}

4 de septiembre.

El Nacional, Diario libre de la Noche.

(Número 90), 6 de septiembre de r9I6, p. 3.

"Estos dos Mancebos..."

No acabo de sorprenderme de la magnificencia rítmica de América. Estos dos mancebos, casi dos niños, José Gorostiza Alcalá y Bernardo Ortiz de Montellano, me han dado la última muestra de la ciencia infusa que vivifica a la mocedad. Un portento se opera: los principiantes de dieciocho años comparten la armonía, la seriedad, $y$, sobre todo, la santidad del apogeo viril. Sí, la actual poesía es santa, por su eficaz heroísmo, por su trascendencia, por la circunspección con que trata los negocios del espíritu y por sus modales caritativos. Aun en sus casuales impericias, Ortiz de Montellano, camarada de los peces de colores, y Gorostiza Alcalá, ahijado de la Luna, son candidatos a la canonización. Que no prevariquen.

RAMÓN LóPEZ VELARDE

El Universal, domingo, 24 de agnsto de rorg

(en la Página Literaria dirigida por Rafael López). 
Alfonso Reyes. El plano oblicuo. Madrid, r920. En $8^{\circ}$

En el grupo de nuestros buenos prosistas - Tablada, López, Orozco Muñoz, Torrì, para no citar otros-Alfonso Reyes representa lo que pudiéramos llamar el parpadeo fosfórico del estilo.

$\mathrm{Su}$ prosa es fosfórica en el sentido de la titilación cerebral y en el sentido de la emoción, porque aun ésta se tine de colores intelectuales, casi siempre graciosos.

Mucho se ha hablado de las capacidades para la prosa en relación con la vocación para la poesía. Lo cierto es que no se puede suscribir una regla terminante. Si hemos tenido grandes poetas, aptos para la prosa (Díaz Mirón, por ejemplo) en otros no ocurre igual.

Lo que sí parece comprobarse es que cuando el poeta sobresale por su disciplina netamente artística, su prosa descuella. Tal es el caso de Reyes, por más que lo prefiramos, en definitiva, fuera de la lírica.

$\mathrm{Ni}$ que decir que su personalidad rebasa los límites de una nota volandera.

Para la joven generación es Alfonso Reyes un modelo de perspicacia, de ondulación, de seso y de lectura. Quizá con demasiada experiencia de los libros, en cuanto que ciertas fragancias juveniles se hallan amortigua. das en él.

El volumen a que nos referimos hoy, compuesto de prosas de años muy anteriores, exhibe, como sus libros más recientes, ese donaire intelectivo a que aludiamos al principio, donaire tan vigoroso que se resuelve, a veces, en guarismos de razón pura.

Esta manera de desencadenar los tipos y las situaciones, extrayéndoles su ideología espectral y haciendo que la pasión misma se desenlace en muecas de filósofo, es una de las operaciones principales que ejecuta Reyes, y la señal primera y concluyente de su fuerza.

También es su riesgo... Felizmente, el autor de "Cuestiones estéticas" atesora fibras vitales, malicia y numen que lo librarán de despistarse en vías discursivas.

Estamos seguros de que seguirá dándonos, como hasta aquí, el esqueleto de la idea y la emoción palpable, la vitrina en que sueñan las materias grises y el tallo en que respiran los cinco sentidos. 
Nos lo fían así su virtud humana y su travesura, que no cesa de pestañar.

\section{R. L. V.}

México moderno, Año I (Núm. 5), I de diciembre de I920, pp. 322-323.

Arturo Ambrogi. El libro del Trópico. Imprenta Nacional de San Salvador. 1918 .

Un libro tropicalmente feo. Uno de esos fárragos, sin expresión moral ni artística, que se escriben a millares en castellano.

El señor Ambrogi, en 352 páginas de tipo menudo, echa mano de ese sistema explicativo, enumerativo y abusivo llamado por alguien "el escrípulo de los iliteratos".

No se podría decir si para la historia de las costumbres encierra alguna utilidad el pesado volumen. Lo que consta es que bajo la carrocería de su prosa sucumbe la intrepidez del lector.

El paisaje y la existencia criollos, requieren, para su interpretación y esterilización, una pluma de calidad, a fin de no caer en los inventarios de un servil naturalismo.

\section{R. L. V.}

México moderno, Año I (Núm. 7), I de febrero de I92I, p. 72.

Fernández Moreno. Campo Argentino. Vol. en $8^{\circ}$ Buenos Aires. Imprenta Mercatali. r9r9. Versos de Negrita. Vol. en $8^{\circ}$ Buenos Aires. Imprenta Mercatali. I920.

Este poeta es un cultivador, frecuentemente acertado, del sincerismo. Un poeta evidente y un artista sin hacer.

El problema de la forma (forma visible o forma interior) existirá siempre, sobre los intentos de anarquía o los simples desenfados de ejecu- 
ción. La sensibilidad exige contornos y la forma es el ángulo facial de cualquier poeta.

Por esto, Campo Argentino, exceptuando media docena de páginas, me parece una intención. En el desarrollo del libro, Fernández Moreno se encuentra con el escollo de la sinceridad sistemática, aplicable a la vida cotidiana: lo trivial.

Versos de Negrita acusa una jornada más en el dominio de las hechuras. "Algún día serás un esqueleto, juguete de marfil dentro de un féretro..." Aquí está ya el embeleso del oficio, la visita de las tijeras. El novio de Dalmira las manejará cada día mejor, porque ha demostrado sus capacidades.

Sustancialmente, Fernández Moreno es uno de los personajes interesantes del Sur. Ha dicho palabras muy humanas. Su naturalidad y su entereza lo distinguen. A un rico le escribe unos versos "para que le regale una casa"; a otro le pide que lo tome de peón...

Es de los que tienen buen surtido de vituallas. Por su virilidad, se desprende de la turbamulta de bufones indefinibles. Una de sus ideas fijas, trabajar.

Lo aplaudimos con simpatía. La cuerda que pulsa se halla amenazada por especies toscas; pero hay linaje espiritual para luchar con ellas. Lo demás -como él mismo expresa hablando de las rosas - lo hace el viento.

R. L. V.

México moderno, Año I (Núm. 7), I de febrero de I92I, P. $7^{1}$. 